\title{
PHYSIOLOGICAL AND PHARMACOLOGICAL MANIPULATIONS WITH LIGHT FLASHES
}

\author{
Henry A. Lester and Jeanne M. Nerbonne \\ Division of Biology 156-29, California Institute of Technology, Pasadena, \\ California 91125
}

\section{INTRODUCTION}

In the experiments described here, a physiological measurement is made while photochemical procedures are employed to alter $(a)$ the concentration of a ligand near membranes or proteins or $(b)$ the structure of the ligand-receptor complexes. Because photochemical reactions often provide the quickest way to produce such chemical perturbations, we emphasize the kinetic information that such experiments have yielded. This information requires a suitably rapid physiological measurement, usually an electrical or optical one. The results often complement those obtained with other kinds of kinetic investigation (iontophoretic application of drugs, stopped-flow mixing, temperature jump, etc). Pharmacological manipulations with light flashes are especially useful for biological systems that cannot be flowed, for instance membranes under electrophysiological investigation or solutions at very low temperatures.

In a conceptual sense, this chapter could treat flash-photolysis investigations of heme proteins; but the topic has recently been reviewed authoritatively (84). This review does not concern photoaffinity labeling (28) or studies on fluorescence recovery after photobleaching. 


\section{PHOTOCHEMICAL STRATEGIES}

\section{General Constraints}

For pharmacological experiments with light flashes, one requires a photosensitive molecule that satisfies several criteria.

1. The compound must be soluble in aqueous solutions of moderately high ionic strength.

2. The photochemical reaction must also proceed in this medium.

3. The photochemical reaction should take place instantaneously with respect to the time scale (usually milliseconds to seconds) of the physiological phenomenon being studied, without the formation of reactive intermediates or active by-products.

4. The photoproduct should be stable (thermally and solvolytically) on the same time scale so that the flash produces a true "concentration jump" of active molecules. (On the other hand, for some studies it may be quite useful to generate a "concentration pulse" if the time course of the pulse is accurately known.)

5. The photochemical reaction should proceed at wavelengths long enough to cause no significant damage to cellular components. A tentative guideline for this criterion would be $\lambda>300 \mathrm{~nm}$, although an efficient photochemical strategy might produce acceptably low damage for wavelengths down to about $250 \mathrm{~nm}$.

6. The efficiency per incident photon should place the reaction within reach of flashlamps and collimated (rather than focused) pulsed lasers. A tentative guideline for this requirement is that the extinction coefficient, $\varepsilon$, times the quantum yield, $\phi$, for the reaction should exceed about 500 .

7. Both the precursor and the photoproduct should have simple, wellcharacterized equilibrium effects on the physiological system; there should be no complicating interactions with proteins or membranes.

These combined constraints are known to be satisfied by only a few of the many available photochemical processes and photosensitive molecules.

\section{Photoisomerization}

CIS-TRANS PHOTOISOMERIZATION OF AZOBENZENES Azobenzene and many of its derivatives can exist in both cis and trans configurations with respect to the axis of the azo nitrogens. 


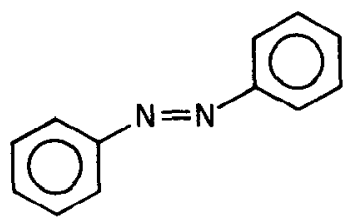

trons

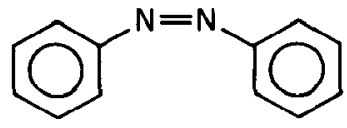

cis

The trans configuration is planar; but in the cis configuration, steric hindrance between the two ortho hydrogens forces the benzene rings into two planes skewed at $53^{\circ}$ (4). As a result, the two configurations differ in many physical properties such as thermochemistry, dipole moment, and absorption spectra (92). It is not surprising that certain azobenzene derivatives display different pharmacological properties in the two isomeric configurations, as described in more detail below.

Some photoisomerizable azobenzene derivatives have photophysical properties well studied for kinetic experiments on membranes and proteins. The $c i s \rightarrow$ trans and trans $\rightarrow$ cis photoisomerizations are produced by light of wavelengths $410-450 \mathrm{~nm}$ and $300-350 \mathrm{~nm}$, respectively. The photoisomerizations occur within a microsecond after absorption of a photon (94) and with a high quantum yield. Photoisomerization is the only result of photon absorption: there are no long-lived excited states, reactive intermediates, or competing photoreactions. The cis and trans configurations are thermally stable for at least several seconds and, with most of the molecules, for several days. These photoisomerizable compounds have the drawback that flashes lead to a photostationary mixture of the cis and trans configurations, rather than to pure solutions of one or the other configuration. However, the composition of the photostationary state and the rate of approach can be determined experimentally. For a given compound, the composition of the photostationary state depends on the wave-length of irradiation, $\lambda$. If the cis and trans isomers have molar absorption coefficients $\varepsilon_{c, t}(\lambda)$ respectively, and quantum yields $\phi_{c, \ell}(\lambda)$ for photoisomerization, then the mole fraction of cis isomers in the photostationary state is $\varepsilon_{t} \phi_{t} /\left(\varepsilon_{t} \phi_{t}+\varepsilon_{c} \phi_{c}\right)$. For the molecule we have studied in most detail, Bis-Q, the highest percentage of cis, 94-96\%, is produced by $338-341 \mathrm{~nm}$ light $(35,79)$; and $420-440 \mathrm{~nm}$ light produces $66 \%$ trans isomers. In dilute solutions, the photostationary state is approached exponentially with the number of flashes; the intensity $I\left(\lambda, t^{\prime}\right)$ of the flash (where $t^{\prime}$ is time) determines the "rate" constant $K_{c}+K_{t}$ (in units of flash-1), where $K_{c, t}=$ $\int_{\lambda} \int_{t^{\prime}} I\left(\lambda, t^{\prime}\right) \varepsilon_{c, t}(\lambda) \phi_{c, t}(\lambda) d t^{\prime} d \lambda$. For a weak flash of intensity $d K_{c, t}$, the fraction of molecules that undergo photoisomerization is $d K_{c, t}$. Further- 
more, the percentage of cis in the photostationary state is given by $K_{t} /\left(K_{c}+K_{t}\right)$. The parameters $K_{c, t}$ can be determined, for a particular flash intensity and a particular compound, by spectral measurements during the approach to the photostationary state. Thus it is not necessary to know $I, \varepsilon$, and $\phi$ individually. With flashlamps and pulsed lasers, values of about one flash ${ }^{-1}$ can now be achieved for both $K_{c}$ and $K_{t}(65$, 79,81 ), so that a single flash converts the solution most of the way to the photostationary state.

The photoisomerization properties are not expected to be sensitive to any solvent or binding conditions likely to occur in or near biological membranes $(19,27,118)$. These expectations have recently been partially verified with spectral measurements on azobenzene molecules that were covalently bound to bovine serum albumin (95) or to detergent-solubilized membrane proteins (94). Laser flashes photoisomerized these bound molecules with $K_{c, t}$ values identical to those found with the unbound molecules in aqueous solution.

Compound<smiles>[CH2-][NH2+]Cc1cccc(N=Nc2cccc(C[NH2+]C)c2)c1</smiles>

QBr

280<smiles>CN(C)Cc1cccc(NNc2cccc(CBr)c2)c1</smiles><smiles>CN(C)Cc1ccccc1N=Nc1ccccc1CN(C)C</smiles><smiles>CN(C)CCOC(=O)Nc1ccc(N=Nc2ccccc2)cc1</smiles>

EW-1
Action

Reversibly bound agonist

Tethered agonist

Competitive antogonist

Open-channel blocker (locol onesthetic) trans

cis

More active configuration

trons

\author{
trons
}

cis

Figure 1 Photoisomerizable cholinergic compounds designed and synthesized by N. H. Wassermann and B. F. Erlanger. 
In summary, the azobenzene derivatives in Figure 1 fulfill the requirements for calibrated "concentration jumps" that are instantaneous on the time scale of channel gating in biological membranes.

Photoisomerizable azobenzene groups have been incorporated into crown ethers. The two isomers extract alkali metal cations into liquid membranes to differing extents (96). Such molecules also might provide a means for controlling the permeability of biological membranes.

OTHER PHOTOISOMERIZABLE COMPOUNDS Some 2,2' stilbene disulfonates block the anion exchange system of erythrocyte membranes (15, $23)$; and the cis and trans isomers have different potencies $(39,40,97)$. No measurements have been reported on modifications to anion flux during photoisomerization of these compounds.

Cyanine, merocyanine, carbocyanine, and related dyes undergo several types of photochemical reaction. In the best-studied photoisomerization reaction, absorption of a photon by spiropyrans leads to $\mathrm{C}-\mathrm{O}$ bond cleavage, producing a merocyanine (102). Other possible photoreactions include oxidation-reduction, excimer, and long-lived triplet formation. The resulting charge rearrangements lead to photovoltages in lipid bilayer membranes exposed to certain dyes $(11,35,50,51,106,107)$. Experiments are also underway to employ these or similar effects to photostimulate living cells (44; A. Grinvald, personal communication).

\section{Photochemical Cleavage of Blocking Groups}

Several small aromatic groups can be cleaved with light of wavelength greater than $300 \mathrm{~nm}$ in aqueous solution (reviewed in 87). The most common scheme exploits the light-induced internal oxidation-reduction reaction in nitroaromatics with a benzylic hydrogen ortho to the nitro group $(7,78)$. The $o$-nitrobenzyl moiety has been removed photochemically from esters to form carboxylate groups $(12,86)$.

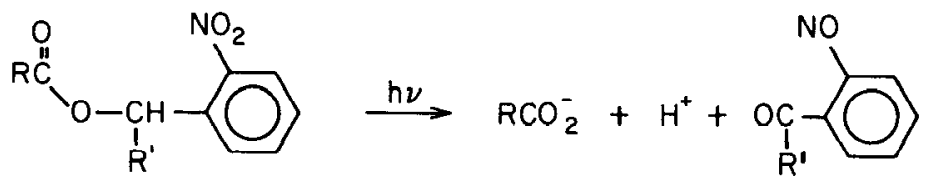

The phosphodiester or phosphotriester is similarly cleaved to form phosphates (56).<smiles>[R]C(OP([R6])(=O)[OH2+])c1ccccc1[N+](=O)[O-]</smiles>

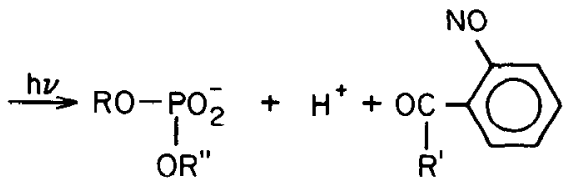


The phosphodiester photolysis has been studied kinetically, as described below; under some circumstances the phosphate is formed within milliseconds (75). In the simplest $o$-nitrobenzyl derivative, $\mathrm{R}^{\prime}=\mathrm{H}$, and the photolysis results in a nitroso aldehyde byproduct $(36,37)$. This aldehyde apparently causes few problems at micromolar concentrations (37); but at higher concentrations it participates in further reactions that vitiate the compounds' usefulness. These problems can be avoided by derivatizing the benzylic carbon, so that the less reactive ketone is formed instead. Thus the $o$-nitrobenzyl group has been photoremoved from compounds in which $\mathrm{R}^{\prime}$ is a phenyl (12), methyl (53), or another o-nitrobenzyl group (86).

In extensions of this technique, 2-nitrobenzyloxycarbonyl and 6nitroveratryloxycarbonyl derivatives of amino groups can be photolyzed to yield the free amino groups $(8,12,86)$.<smiles>[R]N[C+]OC(=O)[CH-]C(=O)c1cc(OC)c(OC)cc1[N+](=O)[O-]</smiles>

Because many neurotransmitters and local anesthetics contain amino groups critical to their function, this reaction is of great potential interest. $o$-Nitrobenzyl ethers have also been prepared and photolyzed to yield hydroxyl groups in phenols $(6)$, sugars $(8,116,117)$, and nucleotides $(14$, $22,83,84)$. Both the amino and hydroxy groups can be photogenerated in aqueous solution, but nothing is known about the speed of the reactions.

The 5-bromo-7-nitroindolinyl moiety is another promising photocleavable group, particularly because photosolvolysis proceeds with light of wavelength $420 \mathrm{~nm}$ (as compared with $350 \mathrm{~nm}$ for the $o$-nitrobenzyl group) $(5,43)$.

\section{SYNAPTIC TRANSMITTERS}

\section{Studies on Nicotinic Acetylcholine Receptors}

ELECTROPHYSIOLOGY Pharmacological manipulations with light flashes complement several powerful electrophysiological methods for kinetic studies on ion channel gating by nicotinic acetylcholine receptors [most recently reviewed in (2)]. In all modern studies, the voltage-clamp technique is applied either to whole cells or to microscopic $\left(\sim 1 \mu \mathrm{m}^{2}\right)$ patches of membrane (44a). Voltage-clamp currents are proportional to the 
number of open channels in the membrane, with a temporal resolution of several tens of microseconds in favorable cases, as the channel population responds to forced or spontaneous perturbations. The available perturbations may be summarized as follows.

1. The neurally evoked postsynaptic current is produced by an impulse that propagates into the presynaptic nerve terminal. A brief but concentrated pulse of acetylcholine is liberated into the synaptic cleft between the presynaptic and postsynaptic cells. Acetylcholine binds to receptors; channels open rapidly so that the current reaches a peak within $\sim 200 \mu \mathrm{s}$; and the transmitter is then efficiently hydrolyzed by acetylcholinesterase as it dissociates from receptors. As a result, very few channels open after the peak. Therefore the neurally evoked postsynaptic current declines exponentially with a rate constant equal to that for channel closing $(2,72,73,111)$.

2. The voltage-jump relaxation is performed in the presence of a constant, externally applied agonist concentration. This experiment exploits the voltage sensitivity of the agonist-receptor interaction, so that the voltage-clamp circuit is employed both to produce the perturbation and to measure its consequences. Voltage-jump experiments give information about both opening and closing rates.

3. In fluctuation analysis, all the stimulating parameters are kept constant and one studies the fluctuations in voltage-clamp currents produced by spontaneous deviations about equilibrium.

4. In favorable circumstances, one can resolve the step-like changes associated with the opening and closing of individual channels (44a).

PHOTOCHEMISTRY Based on earlier studies with blockers of serine esterases (16-18, 38, 54, 109), Erlanger and Wassermann designed and synthesized a series of azobenzene derivatives that interact with nicotinic acetylcholine receptors (Figure 1). These molecules have two crucial properties: $(a)$ they are photoisomerizable, as described above; $(b)$ the two configurations differ in their pharmacological properties.

THE AGONIST, BIS-Q At the nerve-muscle and nerve-electroplaque synapses of several South American and African fishes, trans-Bis-Q acts as a potent but typical nicotinic agonist at concentrations on the order of $10^{-7} \mathrm{M}(13,63,65,81,113)$. At $10^{\circ} \mathrm{C}$ and a membrane potential of -75 $\mathrm{mV}$, it interacts with acetylcholine receptors to open channels with a conductance of $26 \mathrm{ps}$ and a lifetime of $4 \mathrm{msec}^{1}{ }^{1}$ both these values are

\footnotetext{
${ }^{1}$ Known nicotinic agonists induce channels with roughly a tenfold range of durations when tested under identical conditions. The actual duration depends multiplicatively on several conditions, such as temperature, membrane voltage, and synaptic vs extrasynaptic location. Trans-Bis-Q and acetylcholine induce channels of relatively long duration.
} 
identical to those measured with acetylcholine itself under the same conditions (113). The rate constant for opening increases with trans-Bis-Q concentration $(65,81)$. The dose-response curve is sigmoid, with a Hill slope very near 2 (93). The agonist-induced conductance can be blocked by the competitive antagonist, tubocurarine $(63,65)$, and by the "openchannel blocker", QX-222 (65), and desensitizes with continued exposure to Bis-Q.

Electroplaques from the giant Amazonian electric eel, Electrophorus electricus, constitute a particularly suitable preparation for combined electrophysiological and photochemical experiments on Bis-Q. The cis configuration is less than 100 times as potent an agonist as the trans configuration; indeed, any channels induced by solutions of nominally pure cis isomer could be due to trace contamination by trans-Bis-Q. At concentrations of $1 \mu \mathrm{M}$ or less, cis-Bis-Q also shows no inhibitory action, either as a competitive antagonist or as an "open-channel blocker." Thus cis-Bis-Q apparently fails to bind to acetylcholine receptors. This situation made it possible to generate information from two unique types of photochemical perturbation.

The first experiment is the photochemically-induced "concentrationjump" of agonist. One begins with a solution of cis-Bis-Q and uses a flash lamp or, more recently, a pulsed laser to produce a sudden step of trans-Bis-Q concentration. A series of such experiments $(59,61,67)$ culminated in the observation that receptor channels begin to open within $10 \mu \mathrm{s}$ after the first agonist molecules appear near receptors. This datum reduced (by about tenfold) the upper limit on the delay that the agonist-receptor interaction contributes to the transmission of a nerve impulse across a nicotinic synapse. It was hoped that the detailed time course of such "concentration-jump relaxations" would yield new data on agonist-receptor binding, conformational changes, or other events leading to channel activation. An initial delay, in particular, could have been of interest. However, thus far the concentration-jump relaxations have been single exponential functions of time $(63,65,81)$, like voltagejump relaxations and autocorrelation functions measured with Bis- $Q$ and other agonists. The exponential time course is maintained even at the earliest times after the flash, within the resolution of the voltage-clamp circuitry (50-100 $\mu$ s) (M. S. Brodwick, R. E. Sheridan, and H. A. Lester, unpublished).

A second type of photochemical perturbation with Bis-Q has, however, produced uniquely interesting information. In this experiment, a flash produces trans $\rightarrow$ cis photoisomerization of trans-Bis-Q molecules that are bound to receptors with open channels. This photochemical perturbation does not depend on a "concentration jump" of agonist near receptors; it 
is instead a "molecular rearrangement" of the agonist-receptor complex itself. Thus the experiment is analogous to flash-photolysis experiments on liganded hemoproteins, with the difference that subsequent events are monitored with electrophysiological rather than with optical techniques. As a consequence of the trans $\rightarrow$ cis photoisomerization, receptors are no longer occupied by agonist molecules; therefore channels close. The resulting rate of channel closing is one to two orders of magnitude faster than the rate of channel opening produced by the "concentration-jump" described in the preceding paragraph $(61,81)$ and is, in fact, the fastest known kinetic process at acetylcholine receptors. This signal has been termed phase 1; and its speed allows its measurement uncomplicated by slower processes.

Phase 1 has been analyzed for information on the temporal and stoichiometric aspects of coupling between agonist binding and channel activation $(81,93,94)$. The theory is that each receptor's channel remains open if and only if $n$ agonist molecules are present at the receptor's binding site. Thus the channel closes if any of the bound trans-Bis-Q molecules are photoisomerized to the cis configuration. The photon cross section for channel closing is therefore $n$ times that for trans $\rightarrow$ cis photoisomerization. The experiments involved comparing the effects of flashes on $(a)$ the fraction of Bis-Q molecules that undergo trans $\rightarrow$ cis photomerization ( $K_{t}$, measured spectrally) and $(b)$ the fraction of channels that close (measured electrophysiologically as the amplitude of phase 1). The ratio was $n=2.06 \pm 0.09$ (mean \pm SEM). This result provides a very direct confirmation of the concept that the open state of a receptor's channel is much more likely to be associated with the presence of two bound agonist molecules than with a single bound agonist molecule. This result also verifies that both receptor molecules are bound the entire time the channel remains open. It can also be argued, albeit less directly, that at least one agonist molecule leaves the receptor as the channel closes (81).

Bis- $Q$ is much less potent at the acetylcholine receptors of many other teleost fishes (M. E. Krouse, M. M. Weinstock, H. A. Lester, unpublished results), of elasmobranch fishes (60), and of reptiles (M. M. Weinstock, unpublished), producing observable conductances at several tens of $\mu \mathrm{M}$. Kinetic experiments with these less responsive preparations are complicated by the fact that Bis-Q also exerts "open-channel blockade" at such concentrations (3). At frog, rat, and mouse end plates, trans-Bis-Q has no detectable potency as an agonist. Several agonists are known (for instance decamethonium) whose potency differs among nicotinic receptors from various animals, but the species variations seen with Bis- $Q$ are probably the largest reported. The reasons are not known. Perhaps the 
azo double bond interacts strongly with only some receptors (110); perhaps only some membranes are suitable environments for the transBis- $Q$ molecule's combination of large dipole moment accompanied by hydrophobic regions (35).

THE TETHERED AGONIST, QBT Silman \& Karlin (98) designed and synthesized agonists that can be covalently linked to the acetylcholine receptor at a sulfhydryl group (formed by previous reduction with dithiothreitol) near the binding site for agonists. These compounds, which have been termed tethered agonists (65), produce a persistent activation of channels. They offer two advantages for kinetic studies. (a) Tethered agonists eliminate the first step in the agonist-receptor binding reaction, namely the initial, diffusion-limited encounter with receptors. (b) Because the unreacted molecules are washed out of the preparation after the tethering reaction, there is no chance that they can also function as competitive antagonists or "open-channel blockers." Their disadvantage is that, like all known agonists, they eventually desensitize receptors, so that the number of open channels decreases with time $(31,32)$. This shortcoming is avoided by the photoisomerizable tethered agonist, $\mathrm{QBr}(13,65$; Figure 1). $\mathrm{QBr}$ is tethered to receptors in its active, trans configuration and can then be photoisomerized to a predominantly cis mixture that neither opens channels nor desensitizes them, until the moment of the voltageclamp test. This feature, in conjunction with advantage $(b)$ above, may render tethered $\mathrm{QBr}$ a more generally useful ligand than Bis-Q for studies of nicotinic acetylcholine receptors. In addition to Electrophorus electroplaques, $\mathrm{QBr}$ has been tethered to the acetylcholine receptor of skate electroplaques, where its properties resemble those seen with Electrophorus (H. A. Lester, M. E. Krouse, M. M. Weinstock, unpublished). As expected for a tethered agonist, the QBr-induced conductance cannot be blocked by the competitive antagonist, tubocurarine, but remains sensitive to "open-channel blockers" such as QX-222. Also as expected, the relaxation kinetics reveal that the channel opening rate is governed by an intramolecular transition, rather than by a bimolecular process involving free agonist molecules and membrane-bound receptors (65).

Apart from these expected differences, the channels opened by $\mathrm{QBr}$ and other tethered agonists share many properties with those opened by reversibly bound agonists $(31,32,65)$. Channels fluctuate between open and closed states. Voltage-jump relaxations follow an exponential time course; their analysis reveals that the rate constant for channel opening does not depend on membrane voltage, whereas the rate constant for closing depends on voltage to about the same extent as for reversibly bound agonists. The actual magnitudes of these rate constants are about 
twice as great as those seen with $50 \mu \mathrm{M}$ carbachol, a typical reversibly bound agonist, and have the same sensitivity to temperature. As with reversibly bound $\mathrm{Bis}-\mathrm{Q}$, tethered $\mathrm{QBr}$ is an agonist in the trans configuration but tethered cis- $\mathrm{QBr}$ does not open channels. These similarities all suggest that the same rate-limiting step governs the opening and closing of channels for both reversibly bound and tethered agonists. Therefore, this step is probably not the initial, diffusion-limited encounter between agonist and receptor molecules. Instead, the rate-limiting step is some subsequent rearrangement or conformational change of the agonistreceptor-channel complex, as discussed in detail by several authors $(2,42$, $65,72,73)$.

With tethered $\mathrm{QBr}$ as with reversibly bound $\mathrm{Bis}-\mathrm{Q}$, uniquely interesting information comes from experiments in which the agonist-induced conductance is measured while flashes produce molecular rearrangements of the agonist-receptor complex (65). Channels are opened by cis $\rightarrow$ trans photoisomerizations and closed by trans $\rightarrow$ cis photoisomerizations; this cycle can be repeated many times. The kinetics of the relaxations confirm that one is dealing with intramolecular events, with no dependence on free agonist molecules. The amplitudes of the conductance changes were compared with the known photochemical consequences of each flash. The results were analyzed in terms of models that specified $(a)$ whether one or two tethered $\mathrm{QBr}$ molecules were associated with each channel and $(b)$ whether channel opening required that one or two tethered $\mathrm{QBr}$ molecules have the trans configuration. Each scheme predicts a different relation between the fraction of molecules in the trans configuration and the fraction of active receptors. The conclusion was that each channel's activation is controlled by the configuration of a single tethered $\mathrm{QBr}$ molecule. This result is surprising in view of the considerable evidence (some of it discussed above) that two reversibly bound agonist molecules are required to activate a single channel. It may be asked whether this change in functional stoichiometry is caused $(a)$ by the reduction of disulfide bonds in preparation for the tethering reactions, or $(b)$ by the covalent attachment of the agonist molecule. Technical difficulties have thus far prevented a direct answer to this question.

THE PHOTOISOMERIZABLE "OPEN-CHANNEL BLOCKER," EW-1 According to present concepts, local anesthetic molecules act by prematurely terminating the open state of ionic channels in nerve membranes $(1,9$, $20,101)$. Channels open normally, and with normal conductance; but in the open state there is an additional binding site for the blocking molecule. The voltage dependence of blockade for charged blockers suggests that the binding site is within the membrane (2), but it is not yet 
known whether this site is $(a)$ directly within the channel, so that the local anesthetic would act like a plug in a drain, or $(b)$ at an allosteric site elsewhere on the receptor or channel. Also unclear is whether the blocking drug approaches its binding site from the aqueous phase (intracellular for sodium channels and extracellular for acetylcholine receptor channels) or from within the membrane; probably the two routes contribute to varying extents for different blocking molecules.

This model makes the explicit statement that the blocking molecule reaches its binding site only after the channel opens. Thus one predicts that blockade ought to proceed as usual even though the blocking molecule is created after the channel opens. Because the blocking potency of EW-1 (Figure 1) differs in its two configurations, this molecule enabled a test of the prediction (64; Figure 2). The experiment employed the brief pulse of acetylcholine that is released in response to a nerve impulse in the presynaptic terminals. As outlined above, receptors are activated nearly synchronously; acetylcholine is then hydrolyzed rapidly

\section{A Presumed single-channel events}

normal closing:

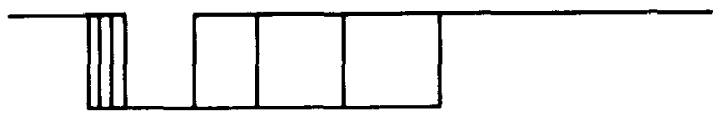

sudden creation of open-channel blocker:

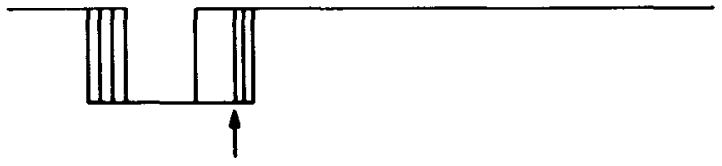

B Postsynoptic currents recorded in the presence of EW-1:

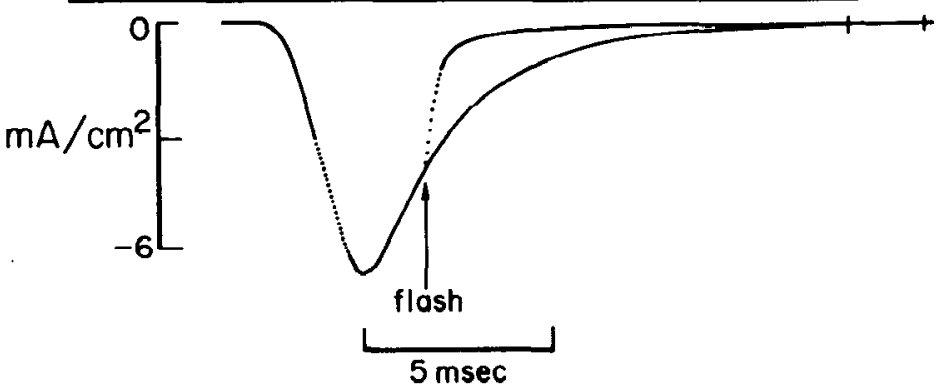

Figure 2 Explanation of an experiment with the light-activated "open-channel blocker", EW-1. 
by acetylcholinesterase, and no more channels open. Thus, the decay phase has an exponential time course formed by the stochastic closing of individual receptor channels. During this decay phase, a flash was delivered to create cis-EW-1, the blocking configuration. The experiment would be more elegant if it employed single-channel recordings like the imaginary ones of Figure $2 A$; but the macroscopic record of Figure $2 B$ plainly shows that the decay phase was accelerated by the flash. Because no channels open during the decay phase, the newly created cis-EW-1 molecules must be prematurely terminating open channels, in agreement with the prediction.

Interestingly, the flash-induced blockade in a given trans-EW-1 solution is temporarily much greater than the steady-state blockade in a nearly pure cis-EW-1 solution of equal concentration (64). Most of the blockade disappears with a time constant of about $300 \mathrm{msec}$. This transient block depends on the time since the flash rather than on the time since the opening of channels. Therefore the transient block should not be confused with the "open-channel blockade" model's prediction that at low agonist concentrations, an open-channel blocker ought to produce major kinetic changes but no appreciable steady-state blockade (2). Instead, the temporarily increased blockade probably arises because EW-1 molecules $(a)$ accumulate at the water-membrane interface with their hydrophobic azobenzene "tails" in the membrane and $(b)$ are liberated near channels by a flash (35). Thus EW-1 exhibits an additional nonspecific interaction with membranes, in violation of constraint No. 7 . This phenomenon could possibly be exploited for information on the extent of local anesthetic penetration into membranes. Also worthy of further study is the prediction that channels ought to conduct again if cis-EW-1 could suddenly be flashed off the binding site.

THE PHOTOISOMERIZABLE COMPETITIVE ANTAGONIST, 2BQ Tubocurarine, the classical competitive antagonist, is thought to block receptors by binding to the agonist site, preventing normal activation. ${ }^{2}$ Little is known about the kinetics of antagonist-receptor binding, however. The pioneering experiments with iontophoretic application yielded an estimate that the tubocurarine-receptor complex has a lifetime of about $2 \mathrm{sec}$ (33), but those data were distorted by buffered diffusion within the synaptic cleft, and more recent experiments suggest a lifetime of several tens of milliseconds at the most $(10,29,30)$. Further progress in understanding these lifetimes may come from experiments employing a "concentration jump" of antagonist during steady activation by agonists.

\footnotetext{
${ }^{2}$ Under some conditions tubocurarine acts in a more complicated fashion, probably because it also exerts "open-channel" blockade (29).
} 


\section{4}

LESTER \& NERBONNE

The photoisomerizable competitive antagonist, 2BQ, can be exploited for such experiments (Figure 1). Dose-response data show that the cis configuration binds about three times more tightly (dissociation constant, $1.5 \times 10^{-7} \mathrm{M}$ ) than the trans isomer (66). The initial experiments with this compound utilized cis $\rightarrow$ trans photoisomerizations while channels were activated by photostable agonists such as carbachol and suberyldicholine; and the conductance increased, as expected (66). In all cases the conductance increase was dominated by a kinetic component with the rate constant of the agonist-receptor interaction ( $1-20 \mathrm{msec})$. Under some conditions there were slower components as well. These results indicate that $2 \mathrm{BQ}$ molecules can vacate receptors so rapidly $(<0.5 \mathrm{msec})$ that agonist molecules can bind to receptors and open channels without a measureable delay. That is, antagonist-receptor kinetics are rapid on the time scale of channel gating. An ambiguity exists: Does this antagonistreceptor lifetime refer to the relatively potent $\mathrm{cis}$ configuration or to the looser (and presumably shorter-lived) trans-2BQ-receptor complex? These issues can be addressed with further experiments, especially ones involving trans $\rightarrow$ cis photoisomerizations, which have become possible recently because of improved light-flash technology.

MOLECULAR SCORECARD In general, the light-flash experiments with nicotinic acetylcholine receptors emphasize the rapid and tight coupling between events at ligand binding sites and events at the ion channel. Channel opening, closing, or blocking is detectable within a few microseconds of a flash-induced molecular rearrangement at the agonist binding site, or even of a "concentration jump" of ligands near receptors. This rapid temporal coupling probably reflects a close physical coupling among the polypeptide chains that comprise a single acetylcholine receptor monomer $(48,57,115)$.

Granted that the light-flash relaxations begin within no detectable delay after the photochemical reaction. A more probing question is whether these relaxations reach completion with the ligand-receptor binding interaction itself or whether the kinetics are governed by slower processes such as conformational changes in the receptor protein $(72,73)$. Probably all investigators would now agree with the latter hypothesis if it were stated a bit more generally: Channel activation requires a further molecular event beyond the mere presence of two agonist molecules at their binding sites. The rate constant for the further transition, if it can be estimated from the leveling off in relaxation kinetics at high agonist concentration (91) or from relaxation kinetics with tethered $\mathrm{QBr}(65)$, is of the order of $1-3 \mathrm{msec}^{-1}$ at $12^{\circ} \mathrm{C}$. According to this view, agonists (and antagonists, judging from the results with $2 \mathrm{BQ}$ ) are equilibrating 
with their binding sites on a more rapid time scale; how much more rapid is not yet certain, particularly since the light-flash studies have not yet revealed a signal associated with ligand binding. However the observed relaxation rates are already so fast that, for ligands at concentrations of $10^{-7} \mathrm{M}$ such as Bis-Q and $2 \mathrm{BQ}$, they make serious demands on the theory of encounter-limited chemical reactions. Perhaps the ligands in question are accumulating in high concentrations at the membrane-water interface $(65,108)$.

There are two possible exceptions to the picture that light-flash relaxations are dominated by intramolecular transitions rather than by binding and dissociation of agonists. (a) During phase 1, channels are closing so rapidly $\left(>10 \mathrm{msec}^{-1}\right.$, even at $\left.10^{\circ} \mathrm{C}\right)$ that this may be the actual rate of cis-Bis-Q dissociation. However, this signal is too rapid for investigation with available voltage-clamp procedure. (b) Most investigators now feel that "open-channel blockade" occurs as the blocking molecule actually enters the channel and binds to a blocking site (2).

One may certainly anticipate further progress in understanding the link between ligand binding and channel behavior. Technical improvements are possible, and underway, in many of the kinetic experiments described here. However, it will be equally important to have more refined structural information on the receptor protein itself. This topic is under investigation in several laboratories.

\section{Studies on Muscarinic Acetylcholine Receptors}

In addition to their effects on nicotinic acetylcholine receptors, all the compounds shown in Figure 1 also interact with muscarinic acetylcholine receptors. At concentrations on the order of $10^{-5} \mathrm{M}$, they block the response to muscarinic agonists in frog heart. This action has been analyzed in detail using Bis-Q. In homogenates of frog heart, trans-Bis-Q blocks the binding of a radiolabeled muscarinic antagonist, $\left[{ }^{3} \mathrm{H}\right]-N$ methylscopolamine, with a dissociation constant of about $4 \mu \mathrm{M}(79,80)$. In voltage-clamped atrial trabeculae from frog heart, trans-Bis- $Q$ inhibits the potassium conductance induced by muscarinic agonists. Doseresponse curves for the agonist carbachol are shifted to the right, suggesting competitive blockade, with a dissociation constant of $5 \mu \mathrm{M}$. Both the binding and dose-response studies show that cis-Bis-Q is about 5-fold weaker as a muscarinic antagonist.

Light-flash experiments were conducted to measure the relaxations of potassium conductance in response to "concentration jumps" of a muscarinic antagonist $(79,80)$. As expected from the equilibrium data, trans $\rightarrow$ cis and cis $\rightarrow$ trans photoisomerizations led, respectively, to increases and decreases of the conductance. Also as expected from previous 
studies using iontophoretic application of agonists, these relaxations contrasted in two ways with those seen at nicotinic receptors. First, they were much slower, requiring several seconds to reach completion. Second, they did not follow a simple exponential time course. Instead, both increases and decreases had an S-shaped waveform, including an initial delay or period of zero slope. The entire waveform of the relaxation, including the delay, was well described by the function $[1-\exp (-k t)]^{2}$, where $t$ is the time since the flash. The rate constant $k$ equaled $3 \mathrm{sec}^{-1}$ at $24^{\circ} \mathrm{C}$ and had a $Q_{10}$ of 2 to 2.5 . However, within the range of conditions that allowed quantitative measurements, $k$ did not depend on the nature of the agonist or on its concentration, on the concentration of Bis-Q, or on the membrane potential. These data indicate that the response to muscarinic agonists requires the sequential completion of at least two steps with roughly equal rates. The data provide little information on the molecular nature of these rate-limiting steps, except to rule out the agonist-receptor binding event. Many studies suggest that intracellular second messengers are involved in the response to muscarinic agonists; and therefore the experiments described in the next two sections may prove relevant for studies of muscarinic responses.

\section{NUCLEOTIDES}

Nucleotides have been generated by the photolysis of $o$-nitrobenzyl phosphate diesters and triesters (Figure 3).

\section{Nucleoside Triphosphates}

"Caged ATP" was originally synthesized and named by Kaplan et al (53). These workers showed that ATP is the only nucleotide formed upon irradiation. Thus, caged ATP is more useful than the $\alpha$-unsubstituted analog; photolysis of the latter compound produces only $25 \%$ ATP, presumably because one of the photoproducts is an aldehyde that reacts with most of the ATP formed by photolysis (86).

Kaplan et al (53) showed that appreciable ATP could be generated from caged ATP after only $1 \mathrm{sec}$ exposure to a mercury arc lamp. More detailed photochemical and information was obtained by McCray et al (75). Although the nitrobenzyl absorption peak is at $265 \mathrm{~nm}$, the action spectum for ATP formation coincides with that for fluorescence excitation, with a peak at $315 \mathrm{~nm}$. The efficiency of ATP formation per photon is decreased by only $50 \%$ at $347 \mathrm{~nm}$, allowing for studies with a doubled ruby laser. This system gave $1 \%$ conversion per millijoule of flash, although absolute quantum yields were not measured. Frequency-doubled 

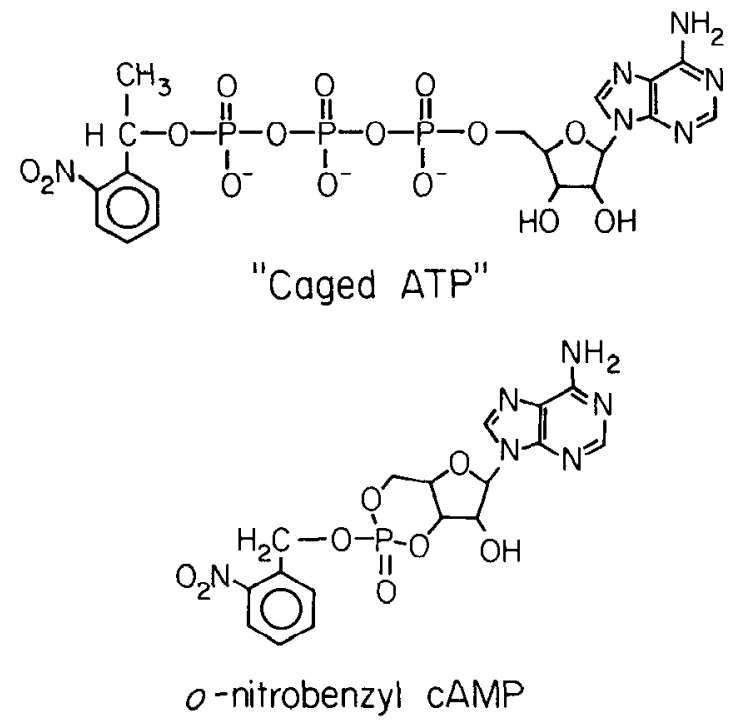

Figure 3 Photolabile esters of nucleotides.

ruby lasers can produce several tens of millijoules at this wavelength, thus affording substantial conversion.

McCray et al (75) also obtained kinetic information. Transient intermediates were followed directly with spectral monitoring; proton release was followed with $\mathrm{pH}$ indicators; and ATP formation was followed by measuring the turbidity decrease upon actomyosin dissociation. Within 5 $\mu \mathrm{sec}$ (the temporal resolution of the instruments) after the flash, a proton is released and an aci-nitro intermediate is formed. This intermediate decays into ATP in an acid-catalyzed step with a rate constant of $2.2 \times 10^{9}\left[\mathrm{H}^{+}\right] \mathrm{sec}^{-1}$ at $22^{\circ} \mathrm{C}$. Thus at $\mathrm{pH} 7$, ATP is formed with a time constant of $4.5 \mathrm{msec}$. The reaction might be faster with suitable substituents on the benzene ring (112).

Caged ATP has desirable biochemical properties. The unphotolyzed molecule seems to be inactive toward ATPases such as the erythrocyte sodium pump (53), the calcium pump of the sarcoplasmic reticulum (47), actomyosin $(49,75)$, and bacterial nitrogenase $(75)$. The only photoproducts are a proton, 2-nitrosacetophenone (which appears to have no harmful effects), and ATP itself. One can thus look forward to useful kinetic data in systems that are rate-limited by ATPases.

The same synthetic techniques would presumably yield photolyzable 2-nitrobenzyl esters of other mono-, di-, and triphosphonucleotides, as well as inorganic phosphate (46) and pyrophosphate. In particular, 
"caged GTP" could become an important tool for exploring biological processes thought to be rate-limited by GTPases. Increased GTP hydrolysis accompanies hormonal stimulation of adenylate cyclase in many tissues $(24,55,62,68)$, and the GTPase step is thought to control the deactivation of adenylate cyclase $(25,26)$. There are also several analogies between this adenylate cyclase system and the regulation of a phosphodiesterase by a GTPase in rod outer segments $(41,69,88)$.

\section{Cyclic Nucleotides}

Simultaneously with the development of caged ATP, Engels and his colleagues prepared 2-nitrobenzyl triesters of cyclic nucleotides. $\alpha$-Unsubstituted esters were used and the aldehyde photobyproducts had no apparent toxic effects on the biological test systems. The 2-nitrobenzyl esters by themselves are not hydrolyzed appreciably by cyclic AMPspecific phosphodiesterase from beef heart; they are weak inhibitors of phosphodiesterase at millimolar concentrations $(37,58)$. At a concentration of $10^{-6} \mathrm{M}$, the $o$-nitrobenzyl triester of cAMP had less than $10 \%$ of the activity of cAMP itself in a protein kinase assay, but full activity was obtained after photolysis (36). These observations indicate that 2-nitrobenzyl triesters bind slightly, or not at all, to intracellular cyclic nucleotide receptors.

The triesters, if dissolved in 1\% dimethyl sulfoxide and applied extracellularly, readily permeate cell membranes. Within a few minutes after exposure to the $o$-nitrobenzyl triester $(100-500 \mu \mathrm{M})$, the physiological effects characteristic of cAMP begin to appear. These include morphological alterations in $\mathrm{C} 6$ glioma cells (37), positive inotroprotic effects in guinea pig heart (58), and spontaneous discharge in Aplysia bag cells (J. M. Nerbonne, L. K. Kaczmarek, and F. Strumwasser, unpublished). Evidently the cAMP is being generated in the cytosol from the $o$ nitrobenzyl triester. It is unclear whether spontaneous hydrolysis alone [half-time of $29 \mathrm{~h}$ at $35^{\circ} \mathrm{C}$ in physiological solution (58)] is rapid enough to account for this reaction; intracellular esterases might accelerate the breakdown of the triester.

It would be of great interest to monitor physiological responses while employing light flashes to accelerate (by many orders of magnitude) the appearance of cyclic nucleotides in the cytosol. The results with caged ATP suggest that such measurements are feasible, at least from the photochemical viewpoint. How rapidly will the "concentration-jump" of cAMP lead to activation of protein kinase, phosphorylation of proteins, and detectable physiological changes? In the heart, there is a lag of a few seconds between the stimulation of $\beta$-adrenergic receptors and the positive chronotropic effect $(82,89)$. Presumably some of this delay involves 
the activation of adenylate cyclase and production of cAMP. The time course of subsequent events would be measured by the experiments suggested here.

\section{INORGANIC IONS}

\section{Calcium}

Normal cells regulate the cytoplasmic concentration of calcium and hydrogen ions at about $10^{-7} \mathrm{M}$. Transient increases above this level occur when $\mathrm{Ca}^{2+}$ enters the cytoplasm either from the external solution or from an intracellular compartment. Increased $\mathrm{Ca}^{2+}$ levels activate muscle contraction, exocytosis, and several enzymes. The intracellular $\mathrm{Ca}^{2+}$ receptor is troponin $\mathrm{C}$ in the case of muscle contraction and the homologous protein, calmodulin, in many other cases.

In some cells, the intracellular $\left[\mathrm{Ca}^{2+}\right]$ increase produces a change in the ionic conductance of a membrane. A calcium-activated $\mathrm{K}^{+}$conductance was first noted in erythrocytes (114) and has now been described for neurons, cardiac muscle, salivary glands, and several other tissues (76). In recent experiments it was shown that $\mathrm{Ca}^{2+}$ is actually activating $\mathrm{K}^{+}$channels $(71,74)$. There remain several questions about the site of $\mathrm{Ca}^{2+}$ action, the kinetics of the membrane response, and the detailed relation between the local $\mathrm{Ca}^{2+}$ level and the membrane conductance. Such problems could be approached with a molecule that releases $\mathrm{Ca}^{2+}$ upon absorbing a photon.

A photosensitive chelator might be obtained by incorporating both ( $a$ ) a photoisomerizable azobenzene group, to obtain large structural differences between cis and trans isomers and $(b)$ several carboxylate groups, to obtain the Ca chelating activity of EDTA and EGTA (see also 103).

$$
{ }_{\left(\mathrm{O}_{2} \mathrm{CH}_{2} \mathrm{C}\right)_{2} \mathrm{~N}-\mathrm{R}} \mathrm{O}=\mathrm{N}-\mathrm{O}
$$

The compound should have the following characteristics:

1. One isomer must chelate $\mathrm{Ca}^{2+}$ with a dissociation constant not exceeding the intracellular $\mathrm{Ca}^{2+}$ concentration $\left(10^{-7}-10^{-6} \mathrm{M}\right)$. For the other isomer, the chelation must be much weaker-preferably by at least tenfold.

2. The compound must discriminate between $\mathrm{Ca}^{2+}$ and $\mathrm{Mg}^{2+}$, with a strong preference for $\mathrm{Ca}^{2+}$-preferably 1000 -fold. 
3. The compound must fulfill the usual requirements for thermal stability of the isomers, speed and efficiency of the photoisomerization, and lack of complicating pharmacology.

It is not yet known whether the desired characteristics can be achieved. As a first approach, the usual $\mathrm{Ca}^{2+}$ indicators were investigated for photolability. Like many azobenzene derivatives, the uncomplexed dye arsenazo III is transiently photochromic on a millisecond time scale (54a), presumably because the photo-generated cis configuration reisomerizes spontaneously with this time course. However it was not possible to demonstrate transient absorption changes or transient $\mathrm{Ca}^{2+}$ liberation from complexes of $\mathrm{Ca}^{2+}$ with arsenazo III, eriochrome black, or 0 cresolphthalein complexone (A. Golob, H. A. Lester, unpublished). The azo bond itself may participate in the chelation and therefore be stabilized in the trans configuration. Similar negative results were obtained in attempts to bleach $\mathrm{Ca}^{2+}$-murexide complexes.

In other initial investigations, Blank et al (21) have synthesized 4,4'bis $\left(\alpha\right.$-iminodiacetic acid) azotoluene, in which $\mathrm{R}$ is a simple $-\mathrm{CH}_{2}$-group para to the azo bond, and tested its ability to chelate $\mathrm{Zn}^{2+}$ ions. The compound is photoisomerizable and the cis configuration binds $\mathrm{Zn}^{2+}$ with an affinity constant of $1.1 \times 10^{5} \mathrm{M}^{-1}$, while binding to the trans configuration is much weaker. Neither isomer binds $\mathrm{Ca}^{2+}$ more tightly than about $10^{3} \mathrm{M}^{-1}$, however (J. M. Nerbonne, unpublished results). In an effort to obtain a higher $\mathrm{Ca}$ affinity, the analog in which $\mathrm{R}$ is a para-ethoxy link was synthesized (Nerbonne, unpublished). This molecule binds $\mathrm{Ca}^{2+}$ with a dissociation constant of about $50 \mu \mathrm{M}$ in the trans configuration and much more weakly in the cis configuration. Thus, progress is being made toward the goal of a light-sensitive $\mathrm{Ca}^{2+}$ chelator.

\section{Protons}

In comparison with $\mathrm{Ca}^{2+}$, much less is known about the possible role of protons as an intracellular messenger. It is clear that many intracellular buffering processes exchange protons for $\mathrm{Ca}^{2+}$ ions-calmodulin and mitochondria are examples-so that any experimental strategy involving "Ca concentration jumps" must also control for, and examine, $\mathrm{pH}$-jumps as well (77).

The difficulties are exemplified in current research on the control of some aspects of intercellular communication mediated by gap junctions. Pioneering studies in this field led to the conclusion that local increases in $\left[\mathrm{Ca}^{2+}\right]$ caused uncoupling $(34,70,90)$. More recent work, however, has stressed the importance of hydrogen ions. Decreases of $\mathrm{pH}$ lead to the 
$\lambda_{\text {max }}, \mathrm{nm}$

\begin{tabular}{|c|c|c|c|}
\hline Structure & Name & $\left(\epsilon, \mathrm{cm} \ell^{-1} \mathrm{~mol}^{-1}\right)$ & $\lambda_{\text {irrad }}, \mathrm{nm}$ \\
\hline & $\begin{array}{c}0 \text { - nitrobenzyl } \\
\text { ocetate }\end{array}$ & $\begin{array}{c}265 \\
(4800)\end{array}$ & $300-366$ \\
\hline
\end{tabular}
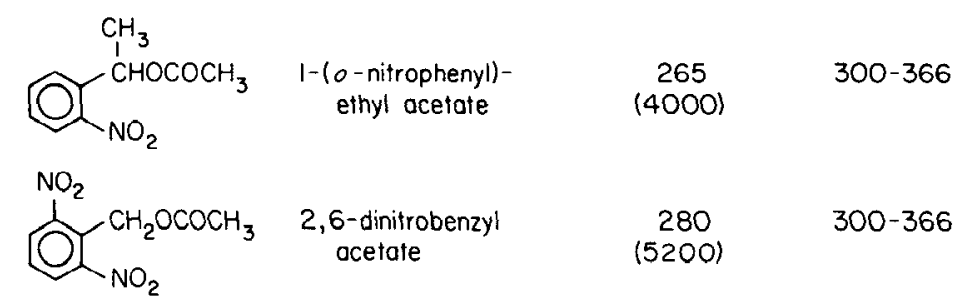

2,6 - dinitrobenzyl
acetate

6-nitropiperonyl

acetate<smiles>CC(=O)OCc1cc2c(cc1[N+](=O)[O-])OCO2</smiles><smiles>COc1cc(OC)c(OC)cc1CCOc1c(COC(C)=O)cc([N+](=O)[O-])cc1OC</smiles>

3,4-dimethoxy-6 nitrobenzyl acetate
280

(5200)

355

(4200)

350

(4300)
300-366

$300-420$

$300-420$

Figure 4 Compounds synthesized for pH-jump experiments. The column labeled $\lambda_{\text {irrad }}$ lists the lowest wavelength that we think will not damage cells and the highest wavelength where the compound absorbs appreciably.

disappearance of electrical coupling in amphibian and fish embryos (89a, $100,104,105)$ and in mouse pancreas (52). It would therefore be of interest to compare the time course of uncoupling after spatially and temporally defined increases of $\left[\mathrm{Ca}^{2+}\right]$ and $\left[\mathrm{H}^{+}\right]$.

With these points in mind, we have synthesized a series of nitrobenzyl esters that can be photolyzed to yield acetic acid and a (hopefully) inactive fragment (Figure 4). The unphotolyzed compounds are soluble in aqueous solution at concentrations up to $10^{-3} \mathrm{M}$ and, being neutral, penetrate biological membranes without the need for micro-injection.

These compounds have been employed in preliminary intracellular "pH-jump" experiments with the gap junctions of Chironomus salivary glands (J. M. Nerbonne, unpublished). The $\mathrm{pH}$ is decreased by a $1 \mathrm{~ms}$ flash from a flash lamp. This leads to uncoupling on a time scale of seconds. Control experiments show that these effects are due to the $\mathrm{pH}$ jump rather than to the flashes alone or to the nitroso photoproducts. It is not yet known whether $\mathrm{pH}$-jump relaxations also occur on the millisecond time scale that characterizes voltage-jump relaxations at gap junctions $(45,99)$. 


\section{GENERATION OF FLASHES}

\section{Flashlamp Systems}

Commercially available flashlamp systems do not produce sufficient intensity for the experiments described in this review. Satisfactory custom-made systems are based on small "short-arc" flash tubes imaged with UV-efficient optics $(79,81)$. The flashes last about $0.5 \mathrm{msec}$.

\section{Laser Systems}

Several types of pulsed lasers produce flashes (duration $<1 \mu \mathrm{sec}$ ) suitable for the photochemical manipulations. Experiments with photoisomerizable azobenzene derivatives utilize a flashlamp-pumped dye laser optimized for $440 \mathrm{~nm}(59,94,95)$ or another one optimized for $350 \mathrm{~nm}$ (R. E. Sheridan and H. A. Lester, unpublished). Experiments on "caged ATP" were performed with a doubled ruby laser at $347 \mathrm{~nm}$ (75).

\section{CONCLUSIONS}

Pharmacological experiments with light flashes are now in various stages of refinement. Useful kinetic information has already been obtained in electrophysiological experiments with photoisomerizable cholinergic compounds. In other areas, such as "caged" nucleotides, the appropriate methods are available but are only now being systematically exploited. In other areas, such as Ca chelators, we probably still lack the necessary photosensitive compounds. Time will tell whether the experiments are focused on the right cells, the right molecules, and the right questions.

\section{ACKNOWLEDGMENTS}

Research in our laboratory is supported by grants from the Muscular Dystrophy Association, the Pew Foundation, and the National Institutes of Health (NS-11756 and GM-29836 and Career Development Award NS-272 to H.A.L.). J.M.N. has been supported by postdoctoral fellowships from the National Institutes of Health and the American Heart Association. During the preparation of this review, H.A.L. enjoyed the hospitality of A. Levitzki and his colleagues in the Department of Biological Chemistry, Hebrew University of Jerusalem.

\section{Literature Cited}

1. Adams, P. R. 1976. J. Physiol. 260:531-52

2. Adams, P. R. 1981. J. Membr. Biol. 58:161-74

3. Adams, P. R., Sakmann, B. 1978. Proc. Natl. Acad. Sci. USA 75:2994-98

4. Allmann, R. 1975. In The Chemistry of the Hydrazo, Azo and Azoxy 
Groups, Pt. 1, ed. S. Patai, pp. 23-52. London: Wiley/Interscience

5. Amit, B., Ben-Efraim, D. A., Patchornik, A. 1976. J. Am. Chem. Soc. 98:843-44

6. Amit, B., Hazum, E., Fridkin, M., Patchornik, A. 1977. Int. J. Peptide Protein Res. 9:91-96

7. Amit, B., Zehavi, U., Patchornik, A 1974. Isr. J. Chem. 12:103-13

8. Amit, B., Zehavi, U., Patchornik, A. 1974. J. Org. Chem. 39:192-96

9. Armstrong, C. M. 1966. J. Gen. Phyisol. 50:491-503

10. Armstrong, D. L., Lester, H. A. 1979. J. Physiol. 294:365-86

11. Baker, J. A., Duchek, J. R., Hooper, R. L., Koftan, R. J., Huebner, J. S. 1979. Biochim. Biophys. Acta 553: $1-10$

12. Barltrop, J. A., Plant, P. J., Schofield, P. 1966. J. Chem. Soc. Chem. Commun. 1966:822-23

13. Bartels, E., Wassermann, N. H., Erlanger, B. F. 1971. Proc. Natl. Acad. Sci. USA 68:1820-23

14. Bartholomew, D. G., Broom, A. D. 1975. J. Chem. Soc. Chem. Commun. 1975:38

15. Barzilay, M., Ship, S., Cabantchik, Z. I. 1979. Membrane Biochem. 2: $227-54$

16. Bieth, J., Vratsanos, S. M., Wasser mann, N. H., Cooper, A. G., Erlanger, B. F. 1973. Biochemistry 12:3023-27

17. Bieth, J., Vratsanos, S. M., Wassermann, N. H., Erlanger, B. F. 1970. Proc. Natl. Acad. Sci. USA 64:1103-6

18. Bieth, J., Wassermann, N., Vratsanos, S. M., Erlanger, B. F. 1970. Proc. Natl. Acad. Sci. USA 66:850-54

19. Birnbaum, P. P., Style, D. W. G. 1954. Trans. Faraday Soc. 50:1192

20. Blackman, J. G. 1959. The pharmacology of depressor bases. $\mathrm{PhD}$ thesis, Univ. New Zealand, Otago

21. Blank, M., Soo, L. M., Wassermann, N. H., Erlanger, B. F. 1981. Science. 214:70-72

22. Broom, A. D., Bartholomew, D. G. 1978. Nucleic Acid Chem. 2:771

23. Cabantchik, Z. I., Knauf, P. A., Rothstein, A. 1978. Biochim. Biophys Acta 515:239-302

24. Cassel, D., Selinger, Z. 1976. Biochim. Biophys. Acta 452:538-51

25. Cassel, D., Selinger, Z. 1977, J. Cyclic Nucleotide Res. 3:11-22

26. Cassel, D., Selinger, Z. 1977. Proc.
Natl. Acad. Sci. USA 74:3307-11

27. Chen, D. T.-L., Morawetz, H. 1976. Macromolecules 9:463-68

28. Chowdhry, V., Westheimer, F. H. 1979. Ann. Rev. Biochem. 48:293-325

29. Colquhoun, D., Dreyer, F., Sheridan, R. E. 1979. J. Physiol. 293:274-84

30. Colquhoun, D., Sheridan, R. E. 1981. $B r . J$. Pharmacol. In press

31. Cox, R. N., Karlin, A., Brandt, P. W. 1979. J. Membrane Biol. 51:133-44

32. Cox, R. N., Kawa, M., Karlin, A., Brandt, P. W. 1979. J. Membrane Biol. $51: 145-59$

33. del Castillo, J., Katz, B. 1957. Proc. R. Soc. London Ser. B 146:339-56

34. De Mello, W. C. 1975. J. Physiol. 250:231-45

35. Duchek, J. R., Huebner, J. S. 1979. Biophys. J. 27:317-21

36. Engels, J., Reidys, R. 1978. Experientia 34:14-15

37. Engels, J., Schlaeger, E. J. 1977. $J$. Med. Chem. 20:907-11

38. Erlanger, B. F. 1976. Ann. Rev. Biochem. 45:267-83

39. Fröhlich, O., Gunn, R. B. 1980. In Genetics, Structure and Function of Blood Cells, Adv. Physiol Sci. ed. F. R. Howllan, G. Gardos, B. Sarkadi, 6:275-80. Oxford: Pergamon

40. Fröhlich, O., Gunn, R. B. 1980. Fed. Proc. 39:1714

4!. Fung, B. K. K., Hurley, J. B., Stryer, L. 1981. Proc. Natl. Acad. Sci. USA 78:152-56

42. Gage, P. W., McBurney, R. N. 1975. J. Physiol. 244:385-407

43. Goissis, G., Erickson, B. W., Merrifield, R. B. 1977. In Peptides, ed. M. Goodman, J. Meienhofer, pp. 559-61 New York: Wiley

44. Grinvald, A. 1978. Neurosci. Abstr. 4:195

44a. Hamill, O. P., Marty, A., Neher, E, Sakmann, B., Sigworth, F. J. 1981. Pflügers Arch. In press

45. Harris, A. L., Spray, D. C., Bennett, M. V. L. 1981. J. Gen. Physiol. 77; 95-117

46. Havinga, E., De Jongh, R. O., Dorst, W. 1956. Recl. Trav. Chim. Pays-Bas 75:378-84

47. Herbette, L., Blasie, J. K. 1980. In Calcium Bonding Proteins, ed. F、 L. Siegel, E. Carafoli, R. H. Kretsinger, D. H. MacLennan, $R$. H. Wassermann, pp. 115-20. Amsterdam: Elsevier-North Holland 
48. Heuser, J. E., Salpeter, S. R. 1975. $J$. Cell Biol. 82:150-73

49. Hibberd, M. S., Goldman, Y. E., McCray, J. A., Trentham, D. R. 1981. Biophys. J. 33:32a

50. Huebner, J. S. 1978. J. Membrane Biol. 39:97-132

51. Huebner, J. S. 1979. Photochem. Photobiol. 30:233-42

52. Iwatsuki, N., Petersen, O. H. 1979. J. Physiol. 291:317-26

53. Kaplan, J. H., Forbush, B., Hoffman, J. F. 1978. Biochemistry 17:1929-35

54. Kaufman, H., Vratsanos, S. M., Erlanger, B. F. 1968. Science 162:1487-89

54a. Kaupp, U. B., Schnetkamp, P. P. M., Junge, W. 1979. In Detection and Measurement of Free $\mathrm{Ca}^{2+}$ in Cells, ed. C. C. Ashley, A. K. Campbell, pp. 287-308. Amsterdam: Elsevier/North-Holland

55. Kimura, N., Shimada, N. 1980. FEBS Lett. 117:172-74

56. Kirby, A. J., Varvoglis, A. G. 1967. J. Chem. Soc. Chem. Commun. 1967:406

57. Klymkowsky, M. W., Stroud, R. M. 1979. J. Mol. Biol. 128:319-34

58. Korth, M., Engels, J. 1979. NaunynSchmiedebergs Arch. Pharmacol. 310:103-11

59. Krouse, M. E., Lester, H. A., Nass, M. M., Nerbonne, J. M., Wassermann, N. H., Erlanger, B. F. 1979. Soc. Neurosci. Abstr. 5:483

60. Krouse, M. E., Lester, H. A., Weinstock, M. M. 1979. Biol. Bull. 157:376

61. Krouse, M. E., Nass, M. M., Nerbonne, J. M., Lester, H. A., Wassermann, N. H., Erlanger, B. F. 1980. In Neurotransmitter and Hormone Receptors in Insects, ed. D. B. Satelle, L. M. Hall, J. G. Hildebrand, pp. 17-26. Amsterdam: Elsevier-North Holland

62. Lambert, M. Svoboda, M., Christophe, J. 1979. FEBS. Lett. 99:303-7

63. Lester, H. A., Chang, H. W. 1977. Nature 266:373-74

64. Lester, H. A., Krouse, M. E., Nass, M. M., Wassermann, N. H., Erlanger, B. F. 1979. Nature 280:509-10

65. Lester, H. A., Krouse, M. E., Nass, M. M., Wassermann, N. H., Erlanger, B. F. 1980. J. Gen. Physiol. 75:207-32

66. Lester, H. A., Nass, M. M. Krouse, M. E., Nerbonne, J. M., Wassermann, N. H., Erlanger, B. F. 1980. Ann. NY Acad. Sci. 346:475-90
67. Lester, H. A., Nass, M. M., Krouse, M. E., Wassermann, N. H., Erlanger, B. F. 1978. Soc. Neurosci. Abstr. 4:370

68. Lester, H. A., Steer, M. L., Levitzki, A. 1982, Proc. Natl. Acad. Sci. USA In press

69. Liebman, P. A., Pugh, E. N. 1979 Vision Res. 19:375-80

70. Loewenstein, W. R., Nakas, M., Socolar, S. J. 1967. J. Gen. Physiol. 50:1865-91

71. Lux, H. D., Neher, E., Marty, A. 1981. Pflügers Arch. 389:293-95

72. Magleby, K. L., Stevens, C. F. 1972. J. Physiol. 223:151-71

73. Magelby, K. L., Stevens, C. F. 1972. J. Physiol. 223:173-97

74. Marty, A. 1981. Nature 291:497-500

75. McCray, J. A., Herbette, L., Kihara, T., Trentham, D. R. 1980. Proc. Natl. Acad. Sci. USA 77:7237-41

76. Meech, R. W. 1978. Ann. Rev. Biophys. Bioeng. 7:1-18

77. Meech, R. W., Thomas, R. C. 1977. J. Physiol. 265:867-79

78. Morrison, H. A. 1969. In The Chemistry of the Nitro and Nitroso Groups, ed. H. Feuer, Pt. 1, pp. 165-213. New York: Wiley

79. Nargeot, J., Lester, H. A., Birdsall, N. J. M., Stockton, J., Wassermann, N. H., Erlanger, B. F. 1982. J. Gen. Physiol. In press

80. Nargeot, J., Nargeot, M.-C., Lester, H. A., Birdsall, N., Stockton, J., Wassermann, N. H., Erlanger, B. F. 1981a. Biophys. J. 33:15a

81. Nass, M. M., Lester, H. A., Krouse, M. E. 1978. Biophys. J. 24:135-60

82. Niedergerke, R., Page, S. 1977. Proc. R. Soc. London Ser. B 197:333-62

83. Ohtsuka, E., Tanaka, S., Ikehara, M. 1974. Nucleic Acids Res. 1:1351-57

84. Ohtsuka, E., Tanaka, S., Ikehara, M. 1978. Nucleic Acid Chem. 1:410

85. Parkhurst, L. J. 1979. Ann. Rev. Phys. Chem. 30:503-46

86. Patchornik, A., Amit, B., Woodward, R. B. 1970 . J. Am. Chem. Soc. 92:6333-35

87. Pillai, V. N. 1980. Synthesis-S 1980: 1-26

88. Pober, J., Bitensky, M. S. 1979. Adv. Cyclic Nucleotide Res. 11:265-301

89. Reuter, H. 1974. J. Physiol. 242:42951

89a. Rink, T. J., Tsien, R. Y., Warner, A. E. 1980. Nature 283:658-60

90. Rose, B., Loewenstein, W. R. 1976. J. Membrane Biol. 28:87-119 
91. Sakmann, B., Adams, P. R. 1979. Adv. Pharmacol. Ther. 1:81-90

92. Shaw, R. 1975. See Ref. 4, pp. 53-68

93. Sheridan, R. E., Lester, H. A. 1981. Biophys. J. 33:14a

94. Sheridan, R. E., Lester, H. A. 1981. In preparation

95. Sheridan, R. E., Lester, H. A., Wassermann, N. H., Erlanger, B. F. 1981. In preparation

96. Shinkai, S., Nakaji, T., Ogawa, T., Shigematsu, K., Manabe, O. 1981. $J$. Am. Chem. Soc. 103:111-15

97. Ship, S., Shami, Y, Breuer, W., Rothstein, A. 1977. J. Membrane Biol. 33:311-23

98. Silman, I., Karlin, A. 1969. Science 164:1420-21

99. Spray, D. C., Harris, A. L., Bennett, M. V. L. 1981. J. Gen. Physiol. 77: 77-93

100. Spray, D. C., Harris, A. L., Bennett, M. V. L. 1981. Science 211:712-15

101. Strichartz, G. R. 1973. J. Gen. Physiol. 62:37-57

102. Sturmer, D. M. 1977. In The Chemistry of Heterocyclic Compounds, ed. A. Weissberger, E. C. Taylor, 30: 441-587. New York: Wiley/Interscience

103. Tsien, R. Y. 1980. Biochemistry 19:2396-2404
104. Turin, L., Warner, A. E. 1977. Nature 270:56-57

105. Turin, L., Warner, A. E. 1980. $J$. Physiol. 300:489-504

106. Ullrich, H. M., Kuhn, H. 1969. Z. Naturforsch. Teil B 24:1342

107. Ullrich, H. M., Kuhn, H. 1972. Biochim. Biophys. Acta 266:584-96

108. Van der Kloot, W. G., Cohen, I. 1979. Science 203:1351-53

109. Wainberg, M. A., Erlanger, B. F. 1971. Biochemistry 10:3816-19

110. Wassermann, N. H., Bartels, E., Erlanger, B. F. 1979. Proc. Natl. Acad. Sci. USA 76:256-59

111. Wathey, J. C., Nass, M. M., Lester, H. A. 1979. Biophys. J. 27:145-68

112. Weinstein, J., Bluhm, A. L., Sousa, J. A. 1966. J. Org. Chem. 31:1983-85

113. Weinstock, M. M. 1981. In preparation

114. Whittam, R. 1968. Nature 219:610

115. Wise, D. S., Schoenborn, B. P., Karlin, A. 1981. J. Biol. Chem. 256:4124-26

116. Zehavi, U., Amit, B., Patchornik, A. 1972. J. Org. Chem. 37:2281-85

117. Zehavi, U., Patchornik, A. 1972. J. Org. Chem. 37:2285-88

118. Zimmerman, G., Chow, L.-Y., Paik, U.-J. 1958. J. Am. Chem. Soc. 80:3528-31 


\section{CONTENTS}

High Pressure Effects on Proteins and Other Biomolecules, Karel Heremans

${ }^{18} \mathrm{O}$ AND ${ }^{17} \mathrm{O}$ EFFEcts on ${ }^{31} \mathrm{P}$ NMR AS PROBES OF ENZYMatic ReActions of Phosphate Compounds, Mildred Cohn

Solid and Liquid Behavior of Red Cell Membrane, R. M. Hochmuth

Photosynthetic Bacterial Reaction Centers: Interactions Among THE BACTERIOCHLOROPHYLLS AND BACTERIOPHEOPHYTINS, William W. Parson

Timely Topics in Statistical Methods for Clinical Trials, Thomas A. Louis, Bucknam McPeek, and Frederick Mosteller

CONSIDERATIONS FOR THE DESIGN OF USEFUl SyNThetic OXYGeN Carriers, $T$. G. Traylor and P. S. Traylor

Light Scattering and Absorption as Methods of Studying Cell POPUlation PARAMETERS, Paul Latimer

Physiological and Pharmacological Manipulations With Light Flashes, Henry A. Lester and Jeanne M. Nerbonne

X-Ray Computed Tomography: From Basic Principles to APPLICATIONS, Richard $A$. Robb

Diffusion-Enhanced FluORESCENCE ENERgy TRANSFER, Lubert Stryer, David D. Thomas, and Claude F. Meares

Optical Detection of Magnetic Resonance in Biologically IMPORTANT MOLECULES, Alvin L. Kwiram and J. B. Alexander Ross

Protein Conformation, Dynamics, and Folding by Computer Simulation, Michael Levitt

Skeletal DNA and the Evolution of Genome Size, $T$. Cavalier-Smith

Ultrasonic Tissue Characterization, Melvin Linzer and Stephen J. Norton

Proton Beam Therapy, L. J. Verhey and J. E. Munzenrider

Fast Neutron Radiation Therapy, L. Cohen and $M$. Awschalom

The Role of Microwave Frequency IN EPR SPECTroscopy of Copper COMPLEXES, James S. Hyde and Wojciech Froncisz

Crystallographic and NMR Studies of the Serine Proteases,

Thomas A. Steitz and Robert G. Shulman

Structural Basis of Proton-Translocating Protein Function, $Y u$.

A. Ovchinnikov, N. G. Abdulaev, and N. N. Modyanov

INDEXES

Author Index

Subject Index 